\section{Civitas Revista de Ciências Sociais}

Civitas - Revista de Ciências Sociais

ISSN: 1519-6089

civitas@pucrs.br

Pontifícia Universidade Católica do Rio

Grande do Sul

Brasil

Pinheiro Coelho, Maria Francisca

A democracia no Brasil não é um mal-entendido

Civitas - Revista de Ciências Sociais, vol. 14, núm. 1, enero-abril, 2014, pp. 126-136

Pontifícia Universidade Católica do Rio Grande do Sul

Porto Alegre, Brasil

Disponível em: http://www.redalyc.org/articulo.oa?id=74230601008

- Como citar este artigo

- Número completo

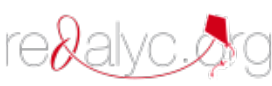

Mais artigos

- Home da revista no Redalyc

Sistema de Informação Científica

Rede de Revistas Científicas da América Latina, Caribe , Espanha e Portugal

Projeto acadêmico sem fins lucrativos desenvolvido no âmbito da iniciativa Acesso Aberto 
Dossiê: Diálogos do Sul

\title{
A democracia no Brasil não é um mal-entendido
}

\section{Democracy in Brazil is not a misunderstanding}

\author{
Maria Francisca Pinheiro Coelho*
}

\begin{abstract}
Resumo: A ideia deste trabalho surgiu da famosa frase de Sérgio Buarque de Holanda, em Raízes do Brasil: "A democracia no Brasil foi sempre um lamentável mal-entendido." Para o autor, inspirado nos tipos ideais weberianos e sob um olhar comparativo, o Brasil com seu homem cordial - aquele que age mais pelo coração do que pela razão - e com o predomínio do espaço privado sobre o público não se apresentava como um solo receptivo aos valores de igualdade da democracia. O texto pretende sugerir que a institucionalização das regras do jogo democrático relativiza o peso da cultura, sem, contudo, alterar seus traços no ritmo compatível com as mudanças das normas. O Brasil, com todos os problemas decorrentes de uma sociedade desigual e hierárquica, situa-se atualmente entre as democracias mais consolidadas da América Latina, que mais interagem e que apresentam disposição para o diálogo.
\end{abstract}

Palavras-chave: Democracia. Cultura política. Instituições. Esfera pública. Esfera privada.

Abstract: The idea for this work came from the famous phrase of Sérgio Buarque de Holanda, in Raizes do Brasil: "Democracy in Brazil has always been an unfortunate misunderstanding." For the author, inspired by the Weberian ideal types and with a comparative view, Brazil with his cordial man - one who acts more by heart than by reason - and with the predominance of the private space on the public one did not appear as a receptive soil to equal values of democracy. The text suggests that the institutionalization of democratic rules relativizes the weight of culture, without changing its traces in the same rhythm of the rule changes. Brazil, with all the problems arising from an unequal and hierarchical society, is currently located among the more consolidated democracies in Latin America, among those that interact more and which have a willingness to dialogue.

Keywords: Democracy. Political culture. Institutions. Public sphere. Private sphere.

* Doutora em sociologia pela UnB, com pós-doutorado na New School for Social Research (Nova York, EUA), e professora titular do Departamento de Sociologia da UnB, em Brasília, DF, Brasil <coelhofrancisca@gmail.com>.

\begin{tabular}{|c|c|c|c|c|c|}
\hline Civitas & Porto Alegre & v. 14 & n. 1 & p. 126-136 & jan.-abr. 2014 \\
\hline
\end{tabular}


A sugestão deste texto é desenvolver um contra-argumento e dialogar com a célebre frase de Sérgio Buarque de Holanda, em Raizes do Brasil: "A democracia no Brasil foi sempre um lamentável mal-entendido". Depois de tanto anos, o livro é de 1936, e diante do hibridismo e complexidade da sociedade brasileira, a ideia que se pretende defender, ao retomar uma obra clássica do pensamento social no Brasil, é a de que Sérgio Buarque tinha e não tinha razão em seu prognóstico.

Para o autor, inspirado nos tipos ideais weberianos e sob um olhar comparativo - entre a Europa e a Península Ibérica e, no interior desta, entre espanhóis e portugueses - virtudes como a lhaneza no trato, a hospitalidade, a generosidade representam um traço definido do caráter do brasileiro. $\mathrm{O}$ Brasil com seu homem cordial, aquele que age pelas leis do coração, com o predomínio do espaço privado sobre o público, das relações pessoais sobre as normas, não se apresentava como solo receptivo aos valores de igualdade da democracia.

Sérgio Buarque esclarece que o conceito de homem cordial não contém em si a conotação de homem bom ou de bondade, mas de ação movida pela emoção. A cordialidade se traduziria na tendência de elevar as motivações afetivas e os interesses familiares acima dos princípios abstratos que devem reger a sociedade moderna e o estado democrático. Explica que a base do conceito é etimológica: o termo cordial vem de core, coração.

Sem deixar de reconhecer o vigor interpretativo e a importância dessa caracterização, defende-se aqui que a institucionalização das regras do jogo democrático relativiza o peso da cultura, a reabsorve e a transmuda no processo de construção da democracia. Com todos os problemas atuais, econômicos, políticos e sociais, o Brasil situa-se entre as democracias mais ativas da América Latina, entre as que mais interagem e que apresentam disposição para o diálogo, marcas de uma cultura da tolerância e receptiva à incorporação de novos valores.

Em uma classificação das democracias na América Latina, no período mais recente, Ignácio Walker (2006) identifica três tipos: a democracia majoritária, na qual vigora a ideia de que basta uma maioria simples para governar e fazer as mudanças consideradas necessárias ou convenientes; a democracia populista ou plebiscitária, na qual há um apelo diretamente dos governantes para as massas substituindo as instituições; e a democracia consensual ou de acordo, que se apoia na vigência e na supremacia das instituições para assegurar a governabilidade democrática.

Segundo o autor, na democracia majoritária está incluída a maioria das democracias presidencialistas da região. Por sua vez, em alguns contextos 
da América Latina, a democracia populista ou plebiscitária é confundida com a democracia participativa. Nessa classificação, o Brasil se incluiria no terceiro tipo, a democracia consensual ou de acordo, que aqui se expressa no que se convencionou chamar presidencialismo de coalizão (Abranches, 1988), modelo na realidade já adotado na maioria das democracias na região (Fabiano, 2006). ${ }^{1}$

Apesar dos problemas de governabilidade na América Latina, a região experimenta uma das situações democráticas mais amplas de sua história republicana e o Brasil se destaca nesse processo. Para desenvolver esse argumento, o presente trabalho está estruturado em três itens: o entendimento sobre a democracia no Brasil; o homem cordial e o predomínio do privado sobre o público; e a relação entre democracia e cultura política.

\section{O entendimento sobre a democracia no Brasil}

A afirmação de Sérgio Buarque sobre a democracia está em desacordo com os dias atuais. Frente à vigência do estado de direito, ninguém se arriscaria em questionar a realidade da democracia no país, apesar de que apenas 29 anos nos separam de uma ditadura militar que perdurou por 20 anos.

Para confluência do estado democrático, diversos fatores externos e internos podem ser apontados: uma tendência mundial de restabelecimento da democracia, iniciada no período pós-guerra (Bobbio, 1986; Hobsbawm, 1995) e continuada no que se convencionou chamar de ondas sucessivas da democracia; a realidade da democracia eleitoral que se estende na América Latina há quase três décadas; o esforço do Brasil de combinar a democracia das urnas com o fortalecimento das instituições.

\footnotetext{
A literatura se divide na avaliação sobre os efeitos do presidencialismo de coalizão no quadro democrático atual. Para uns é uma solução para a governabilidade pelas dificuldades de formação de maiorias diante da quantidade de partidos existentes; para outros, um problema porque da mesma forma que as coalizões garantem a governabilidade, ao possibilitar o Executivo aprovar suas políticas, a ausência de coerência ideológica nas mesmas pode trazer enormes prejuízos, na medida em que enfraquece e compromete o programa político do partido no poder. As coligações subvertem o quadro partidário e as identidades partidárias. Contribuem para a persistência da fragmentação partidária na medida em que colaboram para a permanência de legendas com baixa densidade eleitoral. Para Abranches, tanto o alto fracionamento governamental, quanto uma grande coalizão concentrada, representam uma faca de dois gumes para o presidencialismo de coalizão: "O nó górdio desse sistema é a instabilidade, de alto risco. Sua sustentação baseia-se quase que exclusivamente no desempenho do governo de diferenciar entre o que é ideológico e o que é negociável" (Abranches, 1988, p. 27). Para o autor, como o potencial desse sistema é de alto risco, a tendência é de retirar do programa mínimo as questões mais decisivas. É o caso, como podemos observar, dos governos de Fernando Henrique Cardoso e de Luiz Inácio Lula da Silva, que não conseguiram aprovar reformas substantivas, como a tributária e a política, alardeadas como decisões de governo e promessas eleitorais.
} 
O contraste entre os "ideais democráticos" e a "democracia real" no Brasil, entre as promessas feitas e as não cumpridas, ainda é muito grande, mas não se pode falar de ausência de democracia. Principalmente quando a referência é a democracia formal ou a chamada democracia procedimental. Segundo Bobbio (1986, p. 18), o "único modo de se chegar a um acordo quando se fala de democracia, entendida como contraposta a todas as formas de governo autocrático, é o de considerá-la caracterizada por um conjunto de regras (primárias ou fundamentais) que estabeleçam quem está autorizado a tomar as decisões coletivas e com quais procedimentos".

De acordo com o autor, três são as regras mínimas do jogo democrático: a regra da maioria, ou seja, a base da qual são consideradas decisões coletivas e, portanto, vinculatórias para todo o grupo; a existência de opções de escolhas, isto é, que os que são chamados a eleger sejam colocados diante de alternativas reais e postos em condição de escolher entre uma e outra; a necessidade de que aos que são chamados a escolher sejam garantidos o direito de liberdade de informação, expressão e de reunião. Para essas regras, as normas constitucionais são disposições preliminares que permitem o desenrolar do jogo.

A democracia procedimental, também denominada democracia representativa ou democracia política, está em vigor no Brasil. O debate maior se concentra no aprimoramento dessa democracia, na ampliação da democracia participativa e outras formas de aperfeiçoamento do processo democrático. Fora do âmbito da democracia procedimental, e mesmo ainda nesse aspecto, as carências da democracia no país são grandes, principalmente quando se pensa em termos mais amplos de democracia social e de construção de uma cultura democrática. O sistema de ideias e os valores constitutivos da nação são fortes obstáculos à vida democrática e à recepção do princípio universal da igualdade.

\section{O homem cordial e o predomínio do privado sobre o público}

Se, por um lado, a afirmação de Sérgio Buarque de Holanda hoje soa como anacrônica, por outro, se percebe que os males atuais da democracia no Brasil têm suas origens remotas no prognóstico por ele elaborado: o de que a cultura política no país tem forte vínculo na pessoa, na cultura da personalidade, e não no cidadão, um sujeito jurídico. Com riqueza de detalhes, o autor enfatiza as dificuldades de se instituir no Brasil uma ordem social baseada em normas impessoais e em um ordenamento legal. A referência à pessoa substitui as normas, leis e instituições.

Ao definir que "a democracia no país foi sempre um lamentável mal-entendido", Sérgio Buarque estava contrapondo os valores do libera- 
lismo ao patrimonialismo brasileiro, com suas origens na família patriarcal, instituição social dominante. ${ }^{2}$ Salienta que a família patriarcal transferiu para o espaço público sua visão particularista, vinculando a política a uma extensão do espaço privado familiar:

O quadro familiar torna-se, assim, tão poderoso e exigente, que sua sombra persegue os indivíduos mesmo fora do recinto doméstico. A identidade privada precede sempre, neles, a entidade pública. A nostalgia dessa organização compacta, única e intransferível, onde prevalecem necessariamente as preferências fundadas em laços afetivos, não podia deixar de marcar nossa sociedade, nossa vida pública, todas as nossas atividades. Representando, como já se notou acima, o único setor onde o princípio de autoridade é indisputado, a família colonial fornecia a ideia mais normal do poder, da respeitabilidade, da obediência e da coesão social, sentimentos próprios à comunidade doméstica, naturalmente particularista e antipolítica, uma invasão do público pelo privado, do Estado pela família (Holanda, 1991, p. 50).

Ao longo da história, descreve o autor, observa-se no Brasil o predomínio de vontades particulares sobre uma ordenação impessoal, baseada no estatuto das leis. Nessa ordem social, torna-se difícil aos detentores de posições públicas de responsabilidade a compreensão das distinções fundamentais entre os domínios do privado e do público. Essas esferas se caracterizam justamente pelo que separa o funcionário "patrimonial" do burocrata puro. Para o funcionário "patrimonial", a própria gestão política apresenta-se como assunto de seu interesse particular. As funções, os empregos e os benefícios que deles aufere, relacionam-se a direitos pessoais do funcionário e não a interesses objetivos, como sucede no verdadeiro estado burocrático, em que prevalecem a especialização de funções e o esforço para assegurarem garantias jurídicas aos cidadãos. A escolha dos homens que irão exercer funções públicas faz-se de acordo com a confiança pessoal que mereçam os candidatos e não com suas capacidades próprias. Falta a tudo a ordenação impessoal que caracteriza a vida no estado burocrático (Holanda, 1991, p. 106).

No interior da família nascem as relações que vão predominar na vida pública, que não se constitui como instância independente e autônoma. A família patriarcal fornece o modelo no qual vão se fixar, na vida política, as relações entre governantes e governados. É dela que nasce o predomínio do

2 Diz-se de um tipo de família que se desenvolveu em certas épocas em que o chefe de família ou patriarca, uma autoridade absoluta, resumia toda a instituição social do tempo. 
privado sobre o público e do comportamento sedimentado primordialmente em laços de sangue e afetivos:

E um dos efeitos decisivos da supremacia incontestável e absorvente do núcleo familiar - a esfera, por excelência dos chamados 'contatos primários', dos laços de sangue e de coração - está em que as relações que se criam na vida doméstica sempre forneceram o modelo obrigatório de qualquer composição social entre nós (Holanda, 1991, p. 106).

É desse ambiente que nasce o homem cordial, aquele que age pelas leis do coração:

Essa cordialidade, estranha, por um lado, a todo formalismo e convencionalismo social, não abrange, por outro, apenas obrigatoriamente, sentimentos positivos e de concórdia. A inimizade bem pode ser tão cordial como a amizade, nisto que uma e outra nascem do coração, procedem, assim, da esfera do íntimo, do familiar, do privado (Holanda, 1991, p. 107).

Contudo, observa-se que Raízes do Brasil não é um livro nostálgico e conclusivo a respeito de nosso enquadramento social. Combinando contrastes próprios da lógica dialética, permite também uma visão mudancista do país, que o autor credita às transformações do Brasil arcaico para o moderno. A "nossa revolução", título do último capítulo, residiria nas mudanças do Brasil rural para o urbano. Uma revolução que preservaria as características do homem cordial. Seria uma "revolução com amalgamação", nas palavras do autor, que diz empregar o conceito de revolução no sentido de processo.

Conforme Sérgio Buarque, o percurso que pode estimular o país rumo à democracia contaria a seu favor com algumas características: a repulsa da cultura brasileira pela hierarquia; a relativa inconsistência dos preconceitos de raça e de cor; a receptividade à incorporação de novos valores.

Desse ponto de vista, Raízes do Brasil não é um livro pessimista. Traz à tona as marcas mais profundas da nossa cultura política, presentes até hoje, mas postula mudanças. A atualidade do livro reside em realçar, como traço da cultura política do país, o personalismo. Do tradicional personalismo provém a frouxidão de nossas instituições, prevê o autor. A que outro fator se pode atribuir o "déficit" democrático no Brasil? O autor identifica como principal oposição brasileira o contraste entre os laços familiares, a base da valorização da pessoa, e as exigências de uma sociedade de cidadãos, baseada nos valores da igualdade. 
A título de reflexão, a partir da leitura da obra, pode-se afirmar que a predominância das vontades particulares no espaço público é o mal político maior no país e forte empecilho ao aperfeiçoamento da democracia. Não faltam exemplos na atualidade, sobre a prevalência dos interesses privados sobre os públicos. O cargo público no país é visto como um bem pessoal, uma distinção e um privilégio, e não pela função precípua de servir ao público. Usa-se o cargo como uma vantagem pessoal e a possibilidade de favorecimento individual e da família. Essas dificuldades, que não são exclusividade do Brasil, comprometem a vida pública e a legitimidade dos políticos (Walzer, 2003).

\section{Democracia e cultura política}

Como problematizar a relação entre democracia e cultura política? Essa é uma questão sempre presente nos estudos sobre o tema. No mundo contemporâneo, percebe-se que as diferenças culturais entre os países não têm se constituído em empecilhos à adoção desse regime. Sociedades marcadas por ideologias não igualitárias ingressam no mercado competitivo e têm sido receptivas às regras que combinam desenvolvimento com democracia. Costumes e valores não são empecilhos às escolhas pela via democrática. Não há uma relação mecânica entre cultura política e um determinado regime, embora não se possa negar que valores culturais pesam na construção da democracia (Moisés, 1995). Nesse sentido, exames de culturas específicas sempre vão contribuir para esclarecer opções políticas, mas nunca para determiná-las.

$\mathrm{Na}$ produção acadêmica percebe-se uma nítida distinção entre uma tendência mais culturalista, que sustenta que a democracia requer uma cultura democrática, e uma tendência institucionalista, para quem os fatores institucionais são suficientes para gerar uma explicação convincente da dinâmica da democracia sem que seja preciso recorrer à cultura.

Adam Przeworski, José Antônio Cheibub e Fernando Limongi (2006) levantam a seguinte questão: Será verdade que, para existir e perdurar, uma democracia precisa estar ancorada por uma "cultura democrática"? Os autores argumentam que não e constroem uma tipologia baseada em três visões diferentes sobre a relação entre democracia e cultura política: a visão não culturalista, a culturalista fraca e a culturalista forte.

Para a visão "não culturalista", a cultura não exerceria poder causal para explicar a democracia. Um país não necessita de uma cultura democrática para estabelecer instituições democráticas nem para sustentá-las. Para o ponto de vista "culturalista fraco", uma cultura democrática é necessária para que uma democracia surja e se mantenha, mas a questão da compatibilidade dessa cultura 
democrática com as tradições de sociedade particulares seria controversa, pois essas tradições seriam maleáveis, sujeitas a serem inventadas e reinventadas. Dessa forma, uma cultura democrática poderia florescer mesmo em ambientes culturais aparentemente hostis. Já a visão "culturalista forte" defende que algumas culturas seriam incompatíveis com a democracia.

Os autores criticam o reducionismo da democracia à existência de cultura democrática. Para eles, fatores econômicos e institucionais são suficientes para gerar uma explicação convincente da dinâmica das democracias sem que seja necessário recorrer à cultura. Em defesa da tese, consideram três variáveis em seu modelo "não culturalista" para o estudo da democracia: renda per capita, taxa de crescimento e a taxa de rotatividade dos chefes de governo.

$\mathrm{Na}$ perspectiva deste trabalho, avalia-se que mesmo que se valorizem análises institucionais, deve-se levar em conta a combinação desse enfoque com estudos sobre valores e comportamento político. Ao se adotar a tipologia dos autores acima para estudos sobre a cultura brasileira, poder-se-ia incluir no ponto de vista culturalista fraco Gilberto Freyre, para quem a plasticidade da cultura brasileira não seria empecilho à democracia; na visão culturalista forte, Sérgio Buarque de Holanda e Raymundo Faoro, esse último em uma perspectiva ainda mais pessimista, no que diz respeito ao desenvolvimento da democracia no Brasil. A visão institucionalista seria hegemônica na Ciência Política.

Ao analisar os baixos índices da cidadania ativa no Brasil e o distanciamento entre a prática política e os padrões constitucionais adotados, José Murilo de Carvalho (2000) sugere uma classificação dos pensadores brasileiros, dividindo-os em três grupos. O primeiro seria o dos "pessimistas radicais" que se deixam possuir por sentimentos de desânimo, como se fôssemos condenados, por características inerentes à raça ou à cultura, a permanente inferioridade cívica. Entre eles, estariam Sílvio Romero, Euclides da Cunha, Sérgio Buarque de Holanda e Raymundo Faoro. O segundo seria o dos "otimistas radicais", que enxergam virtudes nas mesmas características nacionais em que outros enxergam vícios. Fariam parte desse grupo, Eduardo Prado, Gilberto Freyre, Roberto DaMatta e Richard Morse. O terceiro grupo, o dos "otimistas pragmáticos", interpreta nossos males como simples sintoma do atraso, suscetível de superação com o tempo e com a adequada ação dos responsáveis pela condução da política nacional. Entre eles, estariam José Bonifácio, Tavares Bastos, Alberto Torres, Oliveira Vianna, e os pensadores marxistas em geral.

Segundo José Murilo de Carvalho, o embate dessas posições encontrou recentemente um analista erudito e arguto em Luiz Werneck Vianna, sobretudo 
nos esforços de usar heuristicamente os conceitos de americanismo e iberismo, apoiando-se no tripé Tocqueville/Gramsci/Morse. Para José Murilo de Carvalho, há caminhos possíveis que podem levar à formação de uma cidadania ativa no Brasil. Cita, como exemplos, a ação do terceiro setor, composto pelas Organizações Não-Governamentais (ONGs), e as experiências dos Orçamentos Participativos em prefeituras.

De acordo com Luiz Werneck Vianna (2000), o fenômeno da democratização da esfera pública no país pode ser medido pela mobilização de entidades da sociedade civil, pelos movimentos de minorias visando o atendimento de reivindicações específicas, pela diversidade de questões levantadas por esses movimentos e pelas manifestações da opinião pública. $\mathrm{O}$ autor analisa a democratização da esfera pública no Brasil em uma dimensão histórico-processual da república. Todavia, chama atenção para a existência de um hiato entre política e sociedade, devido à carência de sentimento republicano, proveniente da tradição predominante do liberalismo das elites.

Como conclusão desse texto, poder-se-ia adiantar que estudos sobre o Brasil com diferentes enfoques, otimistas, pessimistas ou pragmáticos, culturalistas ou institucionalistas, contribuem para pensar os caminhos que podem melhorar a democracia e a cidadania ativa. Nessa direção, Raízes do Brasil é obra extremamente atual, por desvendar a força da visão particularista da política e da invasão do público pelo privado, realidades tão presentes nos dias de hoje.

Na perspectiva introduzida por Sérgio Buarque, o país precisa promover uma revolução com amalgamação, para obter as mudanças almejadas. Sua obra abre caminhos para novos ensaios interpretativos sobre o país. Para um retrato do comportamento político do país, as duas abordagens, a culturalista e institucionalista, podem se complementar, ainda que ancoradas em metodologias distintas.

O sentimento brasileiro de frustração, percebido por Paulo Prado (1997), não no sentido da perda, mas da ausência de um projeto de nação, e o pessimismo como um dos traços dos estudos sobre o Brasil resultam da carência no país da dimensão pública da política. Por outro lado, o otimismo não é senão a negação desse pessimismo e termina, como analisa José Murilo de Carvalho, por enxergar virtudes nas mesmas características nacionais em que os outros enxergam vícios. Uma inversão inócua, pois a aversão às normas e a predominância de laços pessoais na vida pública não podem ser considerados como virtudes da democracia.

Uma leitura do Brasil contemporâneo atesta que a democracia não é um mal-entendido, quando analisada do ponto de vista do funcionamento das 
instituições, do crescimento econômico, da alternância dos governantes e da representação política. Porém, quando examinada no âmbito dos domínios do público e do privado, nos quais se sobrepõem no público os interesses particulares, percebe-se o quanto carece de legitimidade. Mas esse é um viés moral, não provém de uma classe social específica nem dos que estão no poder, mas da sociedade como um todo.

Sérgio Buarque, ao mencionar que a democracia no Brasil sempre foi um lamentável mal-entendido, tinha em mente a oposição entre o estado liberal moderno, regido pela observância a um estatuto jurídico, e a sociedade tradicional, fundada em um ordenamento pessoal, cujos laços primários da família se estendem por toda estrutura social. Enquanto no primeiro modelo a vigência do estatuto da cidadania iguala a todos com respeito aos direitos e obrigações, no segundo predomina a crença na tradição e na legitimidade daqueles que a representam.

Para o autor, os traços patriarcais da cultura brasileira não se adequariam ao modelo do estado de direito democrático. Contudo, seu foco principal na cultura não o impediu de definir os desafios de um projeto democrático, ao se referir a uma revolução com amalgação, como um processo histórico contínuo que levaria o Brasil às mudanças necessárias ao seu desenvolvimento.

\section{Referências}

ABRANCHES, Sérgio Henrique Hudson de. Presidencialismo de coalizão: o dilema institucional brasileiro. Dados, v. 31, n. 1, p. 5-34, 1988.

BOBBIO, Norberto. O futuro da democracia: uma defesa das regras do jogo. Rio de Janeiro: Paz e Terra, 1986.

CARVALHO, José Murilo de. Cidadania na encruzilhada. In: Newton Bignotto (Org.). Pensar a república. Belo Horizonte: Editora UFMG, 2000.

HOBSBAUM, Eric J. Era dos extremos: o breve século XX: 1914-1991. São Paulo: Companhia das Letras, 1995.

HOLANDA, Sérgio Buarque. Raízes do Brasil. Rio de Janeiro: José Olímpio, 1991.

MOISÉS, José Álvaro. Os brasileiros e a democracia: bases sócio-políticas da legitimidade democrática. São Paulo: Ática, 1995.

PRADO, Paulo. Retrato do Brasil: ensaio sobre a tristeza brasileira. São Paulo: Companhia das Letras, 1997.

PRZEWORSKI, Adam; CHEIBUB, José Antônio; LIMONGI, Fernando. Democracia e cultura: uma visão não culturalista. Lua Nova: Revista de Cultura e Política, n. 58, p. 9-36, 2006.

SANTOS, Fabiano. Governos de coalizão no sistema presidencial: o caso do Brasil sob a égide da Constituição de 1988. In: Leonardo Avritzer; Fátima Anastasia (Orgs.). Reforma política no Brasil. Belo Horizonte: Editora UFMG, 2006. 
VIANNA, Luiz Werneck; CARVALHO, Maria Alice Rezende de. República e civilização brasileira. In: Newton Bignotto (Org.). Pensar a república. Belo Horizonte: Editora UFMG, 2000.

WALKER, Ignácio. Qual o caminho da globalização, da democracia e da esquerda na América Latina. Política Externa, v. 15, n. 2, 2000.

WALZER, Michael. Esferas da justiça: uma defesa do pluralismo e da igualdade. São Paulo: Martins Fontes, 2003.

Data de recebimento: 20 set. 2012

Data de aprovação: 25 nov. 2013

Autor correpondente:

Maria Francisca Pinheiro Coelho

Campus Universitário UnB, Departamento de Sociologia

Asa Norte

70910-900 Brasília, DF 